\title{
Reference Range of Chest Expansion in Healthy Adult Living in al-Muthanna Governorate
}

\author{
Ahmed Hasan Reheem ${ }^{1}$, Hussam Riyadh Dakhil ${ }^{2}$, Muslim Talib Jabbar ${ }^{2}$ \\ ${ }^{1}$ Ass. Prof. Dr. Hammurabi Medical College, University of Babylon/Iraq, \\ ${ }^{2}$ Specialist M.B.Ch.B. Al-Muthanna Health Director/Iraq
}

\begin{abstract}
Measurement of chest expansion is one of the important steps in clinical examination of respiratory system and this can be done by chest palpation with hands or more accurately by using of tape measure. Assessment of chest expansion can give an important idea about different disorders in the thoracic cage or in the lung itself by detection of any limitation of chest expansion. Also it used for evaluation of progression and treatment response of many pulmonary, neurological and rheumatological diseases. In number of famous clinical text books the lower normal limit of chest expansion is $5 \mathrm{~cm}$ but we suggest that the reference range of chest expansion is varied in different races. In this study 130 healthy non smoker volunteers living in al-Muthanna governorate, 65 females $(50 \%)$ and 65 males $(50 \%)$, were involved by measuring of their chest expansion with tape measure at level of the fourth intercostal space for two times and best reading was taken for each participant. The body weight of the participants in this study range from $52 \mathrm{~kg}$ to $86 \mathrm{~kg}$ in females and from $50 \mathrm{~kg}$ to $90 \mathrm{~kg}$ in males. According to this study normal range of chest expansion was $(2-5 \mathrm{~cm})$ (mean $=3.35 \mathrm{~cm}, \mathrm{SD}=0.685)$ for females and $(2-5.5 \mathrm{~cm})($ mean $=3.38 \mathrm{~cm}, \mathrm{SD}=0.734)$ for males where the best result was in athletics. There is age wise reduction of chest expansion for both male and female where the mean chest expansion in 18-34 years age group is $3.74 \mathrm{~cm}$ for female and 3.72 for male, in 35-64 years age group is $3.57 \mathrm{~cm}$ for female and $3.66 \mathrm{~cm}$ for male and in those of 65 years and more is $2.63 \mathrm{~cm}$ for female and 2.66 for male. So the chest expansion lower normal limit of participants in this study (as sample of Iraqi people) is vary from other reference ranges. This can be explained by the difference of life style and genetic factors between societies and we should not depend on same reference range for chest expansion in deferent races.
\end{abstract}

Keywords: Chest expansion, Reference range, Tape measure.

\section{Introduction}

Normal chest expansion is vital for respiratory system function and tissues oxygenation and this depend on presence of effective normal thoracic cage mobility and healthy lung where any disorder interfere with chest expansion will affect the oxygen supply of the vital

\footnotetext{
Corresponding Author: Ahmed Hasan Reheem

Ass. Prof. Dr. Hammurabi Medical College, University of Babylon/Iraq

e-mail: qaisajam1981@gmail.com
}

organs of the body. Evaluation of chest expansion is important step in physical examination of respiratory system that include inspection, palpation, percussion and auscultation. Clinically thoracic mobility and expansion can be checked by inspection and manual palpation or use of tape measure which is more accurate, simple and inexpensive method ${ }^{[1,2]}$. The tape measure do not detect any asymmetry in chest expansion, which is useful clue for many underlying respiratory diseases. There are many method for detection of chest expansion by tape measure with little difference. Some of them use level of 4 th intercostal space and repeat the test two times and take the best result while other depend on 6th rib level for measurement of chest expansion: ${ }^{[3,4]}$. Frequent measurements of chest expansion is reliable method for 
severity assessment and treatment response of many primary pulmonary, neurological and musculoskeletal diseases such as such as: chronic obstructive pulmonary diseases, Ankylosing spondylitis, muscular dystrophy and spinal cord injuries ${ }^{[5,6,7]}$. These disorders affect normal movement and expansion of chest and interfere with normal pulmonary function. With good surgical and/or medical treatment including physiotherapy, there will be good chance for chest expansion improvement and regular chest expansion assessment and better to do that with tape measure, as the manual method for chest expansion test is subjective and less accurate can effectively monitor this. Many clinical references consider a difference of more than $5 \mathrm{~cm}$ between full expiration and full inspiration is normal ${ }^{[8]}$. The dependence on same normal range of chest expansion for deferent races is scientifically unaccepted as there is significant genetic and environmental factors determine the body characters of different populations. In male chest expansion is more than that in female because of difference in surface area between the two and respiratory muscle of the male is relatively stronger than female ${ }^{[9]}$. Thoracic cage compliance is reduced with age after third decade of life, according to that the chest expansion will reduced ${ }^{[9,10]}$. Few studies deal with placement of normal range of chest expansion for Iraqi population. This study was done to detect normal chest expansion in healthy adult of al-Mthanna city, Iraq.

\section{Method}

This observational study was achieved at center and periphery of al-Muthenna governorate in Iraq. This study was completed between July 2018 and February 2019. 130 healthy wealthy Persons without history of respiratory disease or smoking or trauma or concurrent disease. The age of participants is 18 years and above of both genders.

Study Protocol: Chest expansion was measured circumferentially with a centimeter tape measure and diametrically transversely by means of tape measure. Readings were carried out in one plane at 4th intercostal space, the difference between deep expiration and deep inspiration has been measured for two times and the best reading was taken, the patient in sitting position.

Statistical Analysis: Data was analyzed by using Primer of Biostatistics. For descriptive statistics mean, standard deviation, proportions and percentages were used. For Analysis of Variance (ANOVA) were used. Statistical significance was taken as $<0.05$.

\section{Results}

Total 130 participants were included in this study. Out of which $65(50 \%)$ were females and $65(50 \%)$ were males.

Table 1: Gender wise mean and range of chest expansion of the study subjects .

\begin{tabular}{|c|c|c|c|c|c|c|}
\hline \multicolumn{3}{|c|}{ Female (n=65) } & \multicolumn{3}{c|}{ Male (n=65) } & \multirow{2}{*}{ P value } \\
\cline { 1 - 5 } Mean (cm) & SD (cm) & Range (cm) & Mean (cm) & SD (cm) & Range (cm) & \\
\hline 3.35 & 0.685 & $2-5$ & 3.38 & 0.734 & $2-5.5$ & 0.815 \\
\hline
\end{tabular}

Mean chest expansion of females was $3.35 \mathrm{~cm}(\mathrm{SD}=0.685)$ and with range of $2-5 \mathrm{~cm}$. Mean chest expansion of males was $3.38 \mathrm{~cm}(\mathrm{SD}=0.734)$ with range $2-5.5 \mathrm{~cm}$, There was no statistically significant difference observed in chest expansion of both genders .

Table 2 Comparison of the Chest expansion means among the studied age groups in female patients.

\begin{tabular}{|c|c|c|}
\hline Age (Years) & Mean Chest expansion (cm) & SD (cm) \\
\hline $18-34$ & 3.74 & 0.46 \\
\hline $35-64$ & 3.57 & 0.56 \\
\hline 65 and above & 2.63 & 0.43 \\
\hline P value & \multicolumn{2}{|c|}{$<0.00001^{*}$} \\
\hline
\end{tabular}


Table 3 Comparison of Chest expansion means among the studied age groups in male patients.

\begin{tabular}{|c|c|c|}
\hline Age (Years) & Mean Chest expansion (cm) & SD (cm) \\
\hline $18-34$ & 3.72 & 0.56 \\
\hline $35-64$ & 3.66 & 0.59 \\
\hline 65 and above & 2.66 & 0.51 \\
\hline P value & & $<0.00001^{*}$ \\
\hline
\end{tabular}

Mean chest expansion of males was $3.72 \mathrm{~cm}$ $(\mathrm{SD}=0.56)$ in $(18-34)$ years, $3.66 \mathrm{~cm}(\mathrm{SD}=0.59)$ in $(35$ - 64) years, $2.66 \mathrm{~cm}(\mathrm{SD}=0.51)$ in ( 65 and above) years .

Mean chest expansion of females was $3.74 \mathrm{~cm}$ $(\mathrm{SD}=0.46)$ in $(18-34)$ years, $3.57 \mathrm{~cm}(\mathrm{SD}=0.56)$ in $(35$ - 64) years, $2.63 \mathrm{~cm}(\mathrm{SD}=0.43)$ in ( 65 and above) years .
In Table no. 2 and 3, It was observed that there was statistically significant age-wise difference in chest expansion values of measurement in both male and female subjects.

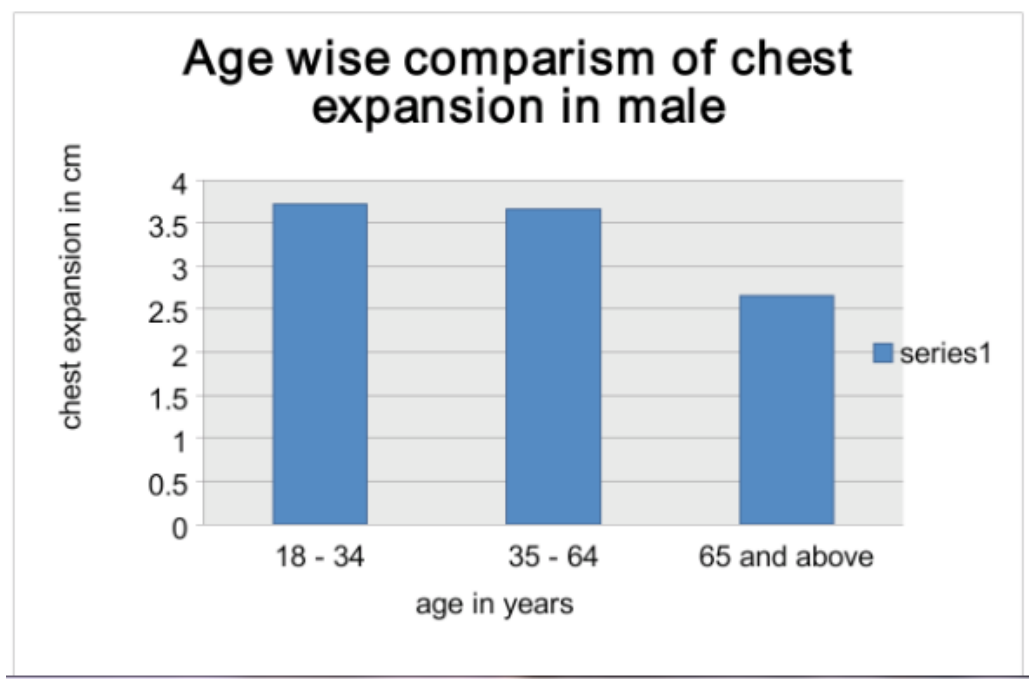

Figure 2 Age wise comparison of chest expansion in Male.

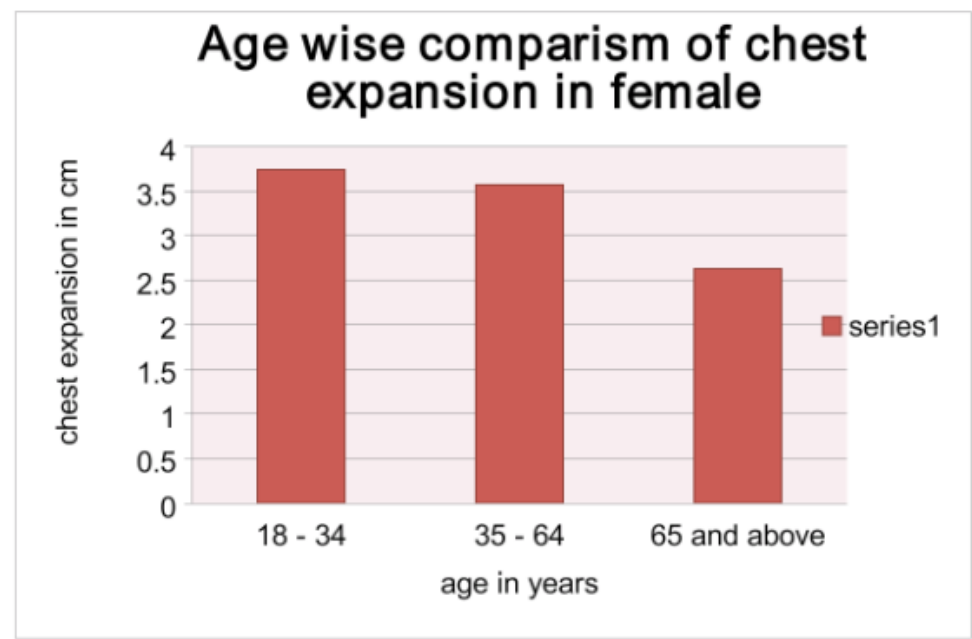

Figure 3 Age wise comparison of chest expansion in Male. 


\section{Discussion}

One of the important steps in physical examination is assessment of chest expansion and this can be done by inspection and palpation with examiner hands(manual) or by tape measure. Several respiratory, neurological and rheumatological disorders can affect normal chest expansion and pulmonary function. Careful regular measurement of chest expansion is important for effective management of these disorders. The reference range of chest expansion in different populations is not the same and special range for each community should be present. In this study we try to determine the reference value of chest expansion for healthy fit adult Iraqi population. Mean chest expansion of female in this study was $3.35 \mathrm{~cm}$ at $4^{\text {th }}$ intercostal space and mean chest expansion of males was $3.38 \mathrm{~cm}$ at the same intercostal space. So the value in female is slightly lesser than that in male and this related to difference in body built of different genders. In our study chest expansion results was higher for younger age group (table 2 and 3 ) and this can be explained by aging effect on musculoskeletal compliance by calcification of the cost chondral cartilage and reduction of elasticity of the thoracic cage connective tissue ${ }^{[11]}$. In comparison with the western population, Iraqis have lesser chest expansion and this may be related to difference in genetic and environmental factors including life style and social activities. Other study showed some sort of relation between body mass index and chest expansion ${ }^{[10]}$ but in our study there is no such relation.

\section{Conclusion}

According to this study, the normal chest expansion range at 4th inercostal space for healthy adults of alMuthanna city in Iraq is $2-5.5 \mathrm{~cm}$. Male has slightly greater value of chest expansion than female and there is decline in chest expansion in older age group for both males and females. There is no significant relation between chest expansion value from one side and height and weight from other side. We focus on vital need for special reference range of chest expansion in each country to reach more accurate diagnosis and assessment of many neurological, pulmonary and rheumatological diseases as there is significant variation in normal chest expansion in different populations. We suggest making larger studies in different areas in Iraq with higher number of participants.
Ethical Clearance: The Research Ethical Committee at scientific research by ethical approval of both MOH and MOHSER in Iraq

\section{Conflict of Interest: Non}

Funding: Self-funding

\section{References}

1- Malaguti, C., Rondelli, R. R., De Souza, L. M., Domingues, M. \& Dal Corso, S. Reliability of chest wall mobility and its correlation with pulmonary function in patients with chronic obstructive pulmonary disease. Respiratory Care (2009) 54, 1703-1711

2- LaPier, T. K. et al. Intertester and Intratester Reliability of Chest Excursion Measurements in Subjects Without Impairment. Cardiopulmonary Physical Therapy Journal (2000) 11, 94-98

3- İlleez Memetoğlu, Ö., Bütün, B. \& Sezer, İ. Chest expansion and modified schober measurement values in a healthy, adult population. Archives of Rheumatology (2016) 31, 145-150

4- Egan's Fundamentals of Respiratory Care, 9th edition. Respiratory Care 54, 545-546 (2009).

5- Bockenhauer, S. E., Chen, H., Julliard, K. N. \& Weedon, J. Measuring thoracic excursion: Reliability of the cloth tape measure technique. Journal of the American Osteopathic Association (2007) 107, 191-196

6- Sharma, J., Senjyu, H. \& Williams, L. Comparison of chest expansion measurement in clients with ankylosing spondylitis and healthy individuals. Journal of Physical Therapy Science 15, 47-51 (2003).

7- Şahin, G. et al. Respiratory muscle strength but not BASFI score relates to diminished chest expansion in ankylosing spondylitis. Clinical Rheumatology (2004) 23, 199-202

8- Douglas, G., Nicol, F. \& Robertson, C. Macleod's Clinical examination 13th ed. The Journal of infectious diseases 209, NP (2013). Pg. No.170

9- Ragnarsdóttir, M. \& Kristinsdóttir, E. K. Breathing movements and breathing patterns among healthy men and women 20-69 years of age: Reference values. Respiration (2006) 73, 48-54 
10- Adedoyin, R. A., Adeleke, O. E., Fehintola, A. O., Erhabor, G. E. \& Bisiriyu, L. A. Reference Values for Chest Expansion among Adult Residents in IleIfe, Nigeria- a Cross-Sectional Study. Journal of Physical Therapy (2013) 6, 54-58
11- Ragnarsdóttir, M. \& Kristinsdóttir, E. K. Breathing movements and breathing patterns among healthy men and women 20-69 years of age: Reference values. Respiration (2006) 73, 48-54. 